\title{
Leadership Development Programs: Investigating the Impact of Contextual and Cultural Factors on LDP Effectiveness in United Arab Emirates
}

Amira Kamali

University of Wollongong in Dubai, United Arab Emirates

Payyazhi Jayashree

University of Wollongong in Dubai, United Arab Emirates

\section{Valerie Lindsay}

American University of Sharjah, United Arab Emirates

\begin{abstract}
:
The interest in leadership continues to grow over the past few decades. Leadership Development Programs (LDPs) have become a priority for all sectors, especially for the public sector. However, LDPs tend to be based on Western leadership theories, and predominantly utilize Western leadership development approaches, and do not consider the influence of national culture in their utilization, namely high-context cultures, as exists in the United Arab Emirates (UAE). This exploratory study focuses on elucidating leadership conceptualizations among Emirati leaders identifying their perceptions of the factors that impact on LDPs and leadership outcomes in the UAE public sector. Semi-structured interviews were conducted with 10 leaders from three Dubai government organisations and data were analyzed using NVivo 10. The significance of the findings of the study are: (1) leadership conceptualizations were based on the common themes of inspiring others and communication, (2) mentoring and coaching were noted to be among the best mechanisms utilized in LDPs, (3) leadership challenges included access to financial resources, adapting to 'smart' government, and building and retention of leaders- hence the need for effective LDPs. The study provides a unique and significant contextual contribution highlighting improvement in opportunities for leadership development programs in the UAE public sector.
\end{abstract}

Paper type: Research paper

Keywords: Leadership, Leadership Development Programs, Leadership Effectiveness, Cross Cultural Understanding, High-Context Culture 


\section{Introduction}

With the rapid economic development that UAE has witnessed in the past three decades, leadership effectiveness is becoming increasingly significant for steering organisational success (Abdalla and Al-Homoud, 2001). As a result, leadership development is emphasized in the Strategic Plan for the Emirate of Dubai 2015 (Dubai Strategic Plan, 2015). Further, the vision of the UAE Vice-President, Prime Minister and the Ruler of Dubai, Sheikh Mohammed bin Rashid Al Maktoum put emphasis on hard work and continuous training to maintain the ability of UAE to cope with changes locally and internationally. Accordingly, many organisations in the UAE have begun to invest in leadership development (Madsen, 2010; Mameli, 2013; Marmenout and Lirio, 2014).

Many organisations consider it necessary to develop effective leaders and seek out successful Leadership Development Programs (LDPs) from other countries. Organisations are spending large sums of money on LDPs annually (Gibler et al., 2000). Even though organisations around the world commonly use LDPs, past research has shown that these organisations actually spend little time on leadership development (Sogunro 1997). According to Collins and Holton (2004), the long term success of an organisation is significantly related with its capability to create efficient and competent leaders. In spite of the potential economic implications associated with the implementation of LDPs, academic research examining leadership competencies and skills among Arab managers is limited. Scholars have, until recently, largely neglected the study of leadership and organisational practices in the Arab context (Abdalla and Al-Homoud, 2001). Focusing more research on leadership and challenges for leadership in the Arab region is important, since there are studies that suggest that these are different to those normally experienced in the Western world (Mameli, 2013), especially in the public sector (Iles et al., 2012). Based on this assumption, many Dubai government organisations in the UAE are considering it necessary to develop effective leaders and seek out successful LDPs that take into account the cultural and Arab context.

However, most LDPs are based on Western leadership theories and models of leadership development, which might be applicable in Western countries, but which might be less effective within other contexts, including the UAE context. This speculation is supported by the finding that national culture plays an important role in determining the effectiveness of leadership development (Mameli, 2013; Marmenout and Lirio, 2014). While this strongly suggests that cross-cultural issues should be considered while designing LDPs for organisations in different countries (House et al., 1996), cross-cultural aspects are still largely under-researched and rarely incorporated into LDPs.

The main purpose of this study is to examine the cultural conceptualization of leadership from a UAE perspective, and identify factors that influence LDP effectiveness in developing leaders. The paper also aims to identify the most effective mechanisms utilized in LDPs operating in the UAE public sector to enhance the development of leadership skills. The underlying mechanisms and determinants of effective LDPs are critical to understand, as the existing literature tends to focus on LDPs practices, rather than the drivers. 
The paper also seeks to identify some key leadership challenges facing government organisations in the UAE. The overarching research questions that the study addresses are: (i) how is leadership conceptualized in a UAE context? And (ii), what factors impact LDPs and the enhancement of leadership in the UAE public sector? To answer these research questions, interviews were conducted with leaders from Dubai government organisations and rich information was collected regarding their expertise in, and expectations of, leadership and LDPs.

\section{Literature Review}

The growing interest on leadership is illustrated by the rising number of literature. In 1948, Stogdill reported that there were 124 books, articles, and abstracts focus on leadership. Sixty years later, Bass and Bass (2008) found 188 articles that are related to leadership published between 1990 and 1999 in just one journal -- Leadership Quarterly. This huge body of research collated by Stodgill has led to over 65 different theories and approaches to conceptualizing and classifying leadership (Mumford, 2000).

Leadership theory assists in providing an understanding of leadership styles and behaviours, but has tended not to account for how these may differ across national cultures. For example, it has been well established from the Global Leadership and Organisational Behaviour Effectiveness (GLOBE) study (House et al, 1999) and others that national cultural context may influence leadership style. Recent research has highlighted the importance of multi-level research on examining the influence of cultural context on leadership, with particular emphasis on the individual level (Herbert et al, 2014; Maznevski et al, 2002; Sharma, 2010; Singelis et al, 1995). This is especially important in countries with high-context cultures, such as the UAE, as an individual level analysis provides a finer-grained view of individual variations across the main cultural dimensions of Hofstede and others (Herbert et al, 2014). Most of the research at the individual level has examined the individualistic-collectivism dimension (Maznevski et al, 2002; Sharma, 2010; Singelis et al, 1995), which is one of the main dimensions separating 'Western' from 'non-Western' countries (Hofsede, 1980).

The following sections outline the main leadership theories noted in the literature, and this is followed by an overview of the more contemporary perspectives of leadership and leadership theory, as well as leadership development programs.

\subsection{Leadership Theories}

Prior to the 1900s, the idea of leadership was centred on Great-Man theories, which argued that great leaders are born, not made. According to Bass and Stogdill (1990), the concept of "Great Man Theory" -- which is also commonly known as the trait approach -- emerged in the 1940s. Then, between 1940 and 1960, the behavioural theories emerged, and the main emphasis was put on the way that leaders do things. Between the late 1960s and the early 1980s, the contingency-situational approach was employed in much leadership research (Fiedler 1964, Hersey and Blanchard, 1969); this focused on the theme that there is no one best Leadership style. What works depends on the situation. For example, Hersey and Blanchard (1969), situational 
leadership theory, proposes that leaders must adapt their leadership style in accordance with varied situations. Hersey and Blanchard noted four leadership styles, which includes telling/ directing, selling/ coaching, participating/ supporting, and delegating/ observing, which must be applied in accordance with the employee maturity level, defined as the level of commitment and competence of employees. The theory of transformational leadership was introduced by Downton (1973) and spurred by Burns in 1978; and describes leadership as a process wherein leaders facilitate achievement of higher level outcomes through motivation, and by communicating values and purpose to followers. Charismatic leadership, which was introduced originally in the seminal work by Weber (1947), is also part of a stream of more contemporary leadership theory.

With regard to the question of whether leadership theories apply universally, Avolio et al (2009) found that, while a number of leadership attributes and behaviours varied across cultures, there were some implicit leadership theories (e.g. charismatic and transformational leadership) that had universal endorsement. However, others have shown differences in the manifestation of leadership theories in different cultural contexts; for example, Van de Vliert (2006) demonstrated an association between charismatic leadership characteristics and national culture context. In this study, high levels of charismatic characteristics were positively related to high levels of in-group collectivism, egalitarianism and performance orientation, while low levels of charismatic leadership ideals were associated with high power distance and uncertainty avoidance.

As outlined in the brief review of the history of leadership development above, leadership theory has evolved from more traditional 'leader-focused' models to the new-genre leadership theories (in which charismatic and transformational leadership models are the most widely studied); these incorporate more pluralistic, multi-level and contextual perspectives (Avolio et al, 2009; Lee, 2014; Lowe and Gardner, 2000). A considerable amount of research has taken place on the relationship between leadership theories, leadership styles, leadership behaviour and national culture, but far less research has been focused on the role of culture in leadership development. The following section reviews some of the relevant literature in this area.

\subsection{Leadership Development Programs (LDPs) and National Culture}

As leadership theories have evolved over time, so too have LDPs, most of which incorporate key elements of leadership theory. However, the evaluation of LDPs, in terms of their relevance and outcomes, has been challenged, with suggestions for reconsideration of the outcome expectations and measures. Notable is the move towards more emergent, relational, approaches to leadership development, the basis of which is concerned less with skill development and more on developing leader mindset (Kennedy et al, 2013). Characteristic of this newer perspective is the ability of the leader to "respond to the complexities of contemporary circumstances seen as requiring a particular adeptness with uncertainty, ambiguity and collaboration" (Kennedy et al, 2013, p.11). Further, the emphasis is not so much on leadership as a phenomenon occurring within, or enacted by, individuals, but rather, a phenomenon occurring between people - hence, a relational perspective. 
Indeed, in recent studies, the value and relevance of the skill-based approach has been challenged, with scholars suggesting that it is too focused on individual competencies, and that outcome evaluation based on scientific measures is inappropriate (Bolden and Gosling, 2006), since these do not reflect meaningful outcomes for an organisation. However, as yet, there is little uptake of these concepts in the development of leadership programs.

What is also striking is the close alignment between the characteristics of a mind-set leadership approach and the recognized cultural dimensions of the UAE and similar high-context cultures. The UAE has high scores on the cultural dimensions of uncertainty avoidance, power distance, masculinity, and collectivism (Hofstede, 2013; Marmenout, 2014). These align well with the attributes associated with a mindset approach to leadership noted above: that is, competence in dealing with uncertainty and ambiguity, and collaboration. Furthermore, high-context cultures usually highlight the importance of relational attributes and interpersonal relationship, which is not featured in traditional LDPs. Hence, alternative models of leadership development similar to the mindset approach may be especially applicable in highcontext cultures.

In summary, LDPs have drawn on the various conceptualizations represented in a range of leadership theories, with the most commonly utilized theories being charismatic and transformational (Avolio et al, 2009). As Carbone (2009) pointed out, just as leadership theories developed over time, the concept of LDPs in organisations has also evolved accordingly. Yet, most of the traditional leadership theories arose in a Western context, which casts doubt on their applicability in other countries, particularly those that are characterized by cultural differences to the Western world. Organisations must, therefore, strive to ensure that they apply LDPs that are contextually relevant and which offer the most suitable approach to leadership development. The UAE is a good example of a high-context culture (Marmenout, 2014) in which to explore these issues further. The study addresses the perspectives of leaders in the UAE on the impact of such differences on their conceptualisation of leadership.

\section{Methodology}

The study employed qualitative methodology, using semi-structured interviews with participants from the Dubai public sector. This enabled questions to be clarified for the interviewee and answers to be followed up as appropriate (Leedy and Ormrod, 2005). Also, semi-structured interviews allow for greater breadth and depth of information to be sought, which may reveal the interviewee experience and give access to their ideas and thoughts (Klandermans and Staggenborg 2002). Furthermore, it permits in-depth exploration of respondent views and perceptions by using question guidelines (Sarantakos 2005). Moreover, semi-structured interviews ensure that all questions are answered by participants, and that they will not receive any assistance from others during the interviews (Barriball and While, 1994).

The application of this approach to this study enabled a deeper understanding how leadership is conceptualized in the UAE, and helped to generate insights and answers to the questions related to leadership conceptualization. In addition, this approach 
facilitated our enquiry into the factors that impact LDPs and the enhancement of leadership in the UAE public sector.

\subsection{Participants, and interview guide and procedures}

Data were collected from interviews with ten participants, comprising CEO's, Directors, Heads of Sections and Heads of Units in three different Dubai public organisations. The participants were all Emirati senior managers, and the questions concerned leadership and LDPs in the context of Emirati employees and managers. Reasons for this included the importance of leadership development in the UAE and the need for a homogenous cultural context in order to address the research question; this is particularly important given the cultural diversity among the UAE-based workforce. The age of participants ranged from 30 to 60 years old, and they were eight males and two females. The interviews were conducted over a period of three months (from May 2014 to July 2014).

An initial letter was sent to the Human Resources Director of each organisation to request the voluntary contribution to the study of the relevant manager/leader in their organisation. Once the approval letter was received from each organisation, the researcher checked on the availability of the potential participants. Then an informed consent form and interview questions were sent by email to potential participants. The email consisted of the names of the researchers conducting the study, the purpose of the study, and the importance of the information which would be obtained from the interview. The participants were asked to review the questions, in order to be prepared for the interview. The researcher conducted the interviews on different days over the three month period.

A standardised interview protocol was prepared for the collection of data (Johnson and Christensen, 2008). The interview protocol consisted of eight theme-based questions and was written in English. The researcher conducted face-to-face interviews in English in the participants' offices, which allowed ease of audiorecording and ensured that participants were able to discuss their experiences in a comfortable setting. At the start of each interview, the purpose of the study was reviewed and the confidentiality procedures were confirmed. The participants were given an opportunity to ask questions for further clarification. Following established protocols for the use of semi-structured interviews (Myers, 2009). The pre-formulated questions were addressed; however, there was not strict adherence to them and new questions that emerged during the interviews were further explored, according to accepted interviewing practice.

The interview questions used in the study focused on gaining information about participants' ideas concerning leadership conceptualization. The first question was designed to examine participants observation related to whether great leaders are born, rather than made as proposed by the Great Man Theory. The purpose of this question was to know if leadership can be learned, in order to develop leadership skills. The rest of the interview consisted of questions that were designed to explore and describe the participants' views on leadership conceptualization and the differences between leadership and management. In addition, specific questions were asked about the importance of cross cultural understanding, and whether or not any

International Journal of Management and Applied Research, 2015, Vol. 2, No. 4 
other contextual considerations might impact leadership effectiveness within Dubai public organisations. Some questions were also directed at identifying specific leadership challenges faced by Dubai public organisations. Finally, participants were asked to consider and reflect their views on the most effective mechanisms used in LDPs which could help to develop the relevant leadership skills. During the interviews, probing questions were used to gather additional information and explanation, in order to provoke greater clarity and depth in the answers. Participants were encouraged to have an engaging conversation about the topics, as this helps ensure that all the questions are answered successfully (Miles and Huberman, 1994). Each interview lasted 30-45 minutes and all interviews were audiotaped for subsequent transcription, as well as to provide more rigour in the study by providing a full record of the interview (Mays and Pope, 1995).

\subsection{Data Analysis Procedure}

All the interviews were transcribed by the researcher who conducted the interviews. The transcripts were reviewed extensively and, using NVivo 10 to assist in the analysis, the research team identified the key themes, which are discussed in depth in the next section. The framework for the coding process reflected the structure of the interview questions. However several additional themes emerged once coding proceeded. NVivo is a software used for analyzing qualitative data from interview transcripts and provides a robust approach for developing codes and themes from interview transcripts (Weston et al. 2001). Since the study is a first-stage exploratory phase of a larger study, the aim was to capture broad perspectives on leadership and LDPs in the UAE, which would be examined in more depth in subsequent phases. For this reason, basic thematic coding of the data was considered adequate for this purpose; however, in-depth reviews of the data by the research team were a critical part of the coding process.

\section{Findings and Discussion}

This section provides a detailed discussion of the main themes that were derived from the data analysis process.

\subsection{Are Leaders Born or Made?}

It was thought for many years that leadership for some people comes naturally and could not be learned (Hernez-Broome and Hughes, 2004; Bass and Stogdill 1990). However, these researchers found that leadership can be learned, and leaders believe it is essential to carry on growing and developing. Successful leaders must learn to develop new traits that encourage subordinates to accomplish greater achievements (Kouzes and Posner, 2002). The assumption that people have the ability to be trained to direct and lead puts the onus on companies to have efficient LDPs that support this learning.

The responses to the first question (whether leaders are born or made) were analyzed to establish whether or not participants' considered that leadership can be learned, and if there is a need for LDPs in Dubai public organisations. The findings do not support the Great-Man theories (Judge et al. 2002), which argue that great leaders are born, not made (Bass and Stogdill, 1990). When the ten participants were asked whether great leaders are born, or made, 80 per cent of the participants agreed that leaders are 
born, and, at the same time can be made by enabling them to develop certain leadership skills. For example, one of the participants mentioned that "leadership can be taught, can be inherited, can be gained." Two participants suggested that leaders are not born as leaders, but can become leaders. One of them stated that "leadership skills can be developed through certain training courses". According to Collins and Holton (2004), an organisation's long term success is strongly connected with its capability to create efficient and competent leaders. Based on this, many Dubai government organisations in the UAE are considering it necessary to develop effective leaders and seek out successful LDPs. The findings overall suggest that senior managers support the role of LDPs in facilitating leadership development in this context.

\subsection{Leadership and Management}

Leadership and management are two different terms that are often confused, and it is important to distinguish between them. Leadership can be defined as the ability to inspire self-confidence and support, along with people who are required to achieve the goals and vision of an organisation, while management can be defined as directing people based on principles or values which have already been established by the organisation (Kim and Maubourgne 1992). The findings show that the majority of the participants understand the difference between leadership and management. They defined leadership as inspiration, motivation, influence, visionary, and taking responsibilities. This supports House and his colleagues' definition of leadership, which is "the capability to influence, inspire, and enable others to have a contribution toward the efficiency and success of the association" (House et al., 1999, p. 184).

On the other hand, most participants defined management as controlling policies, documents and procedures, and that management is about working according to regulations, rules and systems. This supports Kotter (1990), who asserts that management is the ability to master complexity, and the aim of good management is to maintain order and constancy by producing formal plans, designing suitable structures of the organisation, and monitoring outcomes against plans. The findings indicate that the leaders knew the differences between leadership and management very well, and were even aware of different leadership theories and styles. Also, participants mentioned the importance of different leadership skills, such as communication, motivation, problem solving, empowerment, critical thinking and decision making.

Majority of the respondents emphasised communications skills, which they noted as one of the most important skills that any leader should have. According to some participants, a leader should be able to communicate with his/her subordinates and be able to influence them, in order to achieve the organisation's goals. These findings lend support for Hogan's (1994) argument that managers can demand others to perform their tasks because of their "position power", but these managers are not necessarily leaders. True leadership occurs when others willingly accept, for a period of time, the aims of the leader as their own. Therefore, leadership is concerned with developing consistent and goal-oriented teams (Hogan 1994). 


\subsection{Effective Mechanisms in LDPs}

According to Day (2000: 582), "a leadership development approach is oriented toward building capacity in anticipation of unforeseen challenges (i.e. development)". However, a more focused analysis of the findings indicates important conclusions about the most effective mechanism of LDPs in Dubai public organisations. Based on the findings, coaching and mentoring were stated to be the most essential tools recommended for effective LDPs. The results also show that one of the most important leadership skills is effective communication, which, participants suggested, every leader should have.

The majority of the participants in the study noted that coaching and mentoring are the best mechanisms used in LDPs, because they are more practical and effective than training courses. This finding is consistent with the work of Day (2000) which found that coaching and mentoring as one of the most popular practices to develop leaders. As the participants noted, one to one interaction -- which is the main basis for coaching and mentoring -- is more effective than group-based training.

Day (2000) asserts that classroom programs suffer from transfer challenges and high start-up costs, and, consequently, there is a movement towards practicing leadership development in the work setting. In this study, 50 per cent of the participants argued that there is a need for tailored LDPs in Dubai public organisations, and that leaders need to improve their leadership skills by attending customized LDPs. One of the participants added a very interesting point, that LDPs should not be implemented just for a set period of time, but should be a continuous learning process. This statement is in line with Thach and Heinselman (2000) who claim that organisations that utilize ongoing and continuous leadership development methods value the importance of training future leaders and consider it as an area crucial for success.

\subsection{Contextual Considerations in LDPs}

When the participants were asked about contextual considerations that might impact leadership effectiveness within Dubai public organisations, half of the respondents gave the highest rating to cultural understanding. This was followed by organisational contextual factors, most notably, opportunities for exercising leadership. The results showed the importance of cultural considerations in LDPs, where participants agreed that organisations should have special courses to facilitate cross cultural understanding. Importantly, little consideration has been given to integrating cultural issues into leadership development programs in general, and even less within the UAE (Mameli, 2013; Marmenout and Lirio, 2014). Several studies (e.g. Aram and Piriano, 1978; Mameli, 2013; Wright 1981) have identified that leadership style is culturally determined and differs from culture to culture. Accordingly, influences on the effectiveness of LDPs and enactment of leadership might differ as a result of the cultural context in which the leader functions. The importance of incorporating considerations of culture into LDPs was also introduced in the work of Robert House and his colleagues in the GLOBE study, although it is still widely acknowledged that cross-cultural influences on leadership development requires further research (AlMazrouei and Zacca, 2015; Avolio et al., 2009). Consequently, in order for top leaders to lead their organisations in the 21st century, they have to be aware of the national (or regional) and ethnic cultural diversity of their staff and their working 
environments. House stated that it is becoming increasingly obvious that leadership development programs (LDPs) should be modified to recognize the cultural variety embedded in the international context and varying national cultures (House et al, 1996).

In terms of the organisational context of LDPs, Leskiw and Singh (2007) argued that there are some specific factors that influence LPDs effectiveness. These factors include needs assessment, audience selection, organisational infrastructure and learning system. The findings show that some of the participant organisations are following two types of audience selection, which are merit based and random selection. 50 percent of the participants in this study argued that potential leaders should be nominated to attend LDPs instead of attendees being recruited by random selection. They added that one of the most important factors in any LDP is the selection process, and it is critical that the right participants are selected to attend. Past research shows that organisations spend relatively little time on leadership development, and, even though a company may select individuals as potential leaders, evidence suggests that few of them are ready to be successful leaders (Sogunro 1997).

\subsection{Leadership Development Challenges}

Organisations are spending large sums of money on LDPs annually (Gibler et al., 2000). Unfortunately, many organisations are failing to gain maximum advantage from such programs (Hernez-Broome and Hughes 2004). Some organisations are selecting LDP participants randomly, rather than ensuring that their potential leaders join the programs; this undoubtedly impacts on the ultimate effectiveness of the LDPs concerned. The results of our study reveal a number of different challenges associated with leadership development and LDPs. These include access to financial resources, adapting to smart government, and the building and retention of effective leaders. As mentioned by some participants, even when employees are supported through an LDP, lack of opportunity for exercising leadership was a problem and challenge. They argued that managers do not always support their subordinates who complete LDPs and these employees do not, therefore, get the chance to exercise their leadership skills and practice what they have learned from the programs.

\section{Conclusions}

Leadership is an essential ingredient for organisational success, and leadership development programs a recognized vehicle for building effective leaders (Collins and Horton, 2004). Understanding the impact of (national) cultural context on the effectiveness of LDPs is critically important, particularly given that most LDPs have been developed in a Western context. Yet this area has, so far, received relatively little research attention, especially with regard to high context cultures, such as in the UAE.

The seminal works of Hofstede and the more recent GLOBE study clearly identify differences in the manifestation of cultural dimensions between Western and nonWestern cultures (Hofstede, 1980; House et al., 1999). With regard to leadership development, it is evident from recent literature that the cultural dimensions exhibited by non-Western countries are more in line with contemporary leadership development theory (such as the mind-set approach proposed by Kennedy et al 2012), than with the traditional approaches based on skills development. The study addresses the issue of 
the appropriateness of implementing LDPs based on Western leadership theory in non-Western countries and organisations. This issue, along with considerations of the role played by national culture, has formed the rationale for the study.

The findings confirm the importance of leadership and effective leaders in Dubai public organisations. The study focuses on the different themes that emerged during the interviews with senior leaders, including leadership conceptualizations, and effective mechanisms used in LDPs, leadership challenges and contextual factors that impact LDPs effectiveness. The ten leaders interviewed highlighted important aspects relating to leadership conceptualization, as it applies in the UAE. The results also show how participants were able to differentiate between leadership and management. The findings also indicate the views of participants with regards to the best mechanisms to be utilized in LDPs, which included coaching and mentoring, tailored LDPs, continuous learning, knowledge transfer, and work experience. In addition, the research highlights the importance of contextual considerations in LDPs, with a particular emphasis on cultural and cross-cultural understanding, which was considered to be crucial for LDPs being implemented in the UAE.

\subsection{Limitations and Future Research Implications}

The study is a preliminary study into leadership and LDPs in UAE government organisations. Given the nature and scope of the study, it would be difficult to test the relationship between cultural impact and leadership. However, the initial findings lend themselves for further research that can provide a more detailed and fine-grained analysis, using, for example, quantitative methods. Additionally, although the study is focused on the public sector, it has not incorporated any comparative analysis with private sector organisations; this would be an interesting area for further research. Finally, it is important to proceed to an investigation of LDPs in use in similar settings, in order to ascertain whether and how the factors identified in this study impact the implementation and effectiveness of such programs. This will be the basis of the next phase of this research project.

\section{References}

1. Abdalla, I.A, and Al-Homoud, M.A. (2001) "Exploring the implicit leadership theory in the Arabian Gulf states", Applied Psychology: An International Review, Vol 50, No.4, pp 506-531. https://doi.org/10.1111/1464-0597.00071

2. AlMazrouei, H., and Zacca, R. (2015). "Expatriate leadership competencies and performance: a qualitative study", International Journal of Organisational Analysis, Vol. 23, No. 3, pp.404-424. https://doi.org/10.1108/IJOA-07-2014-0781

3. Aram, J and Piraino, T. (1978) "The Hierarchy of Needs Theory: An Evaluation in Chile", International Journal of Psychology, Vol. 12, No. 2, pp. 179-188.

4. Avolio, B. J., Walumbwa, F. O., and Weber, T. J. (2009). "Leadership: current theories, research, and future directions", Annual Review of Psychology, Vol. 60, pp.421-49. https://doi.org/10.1146/annurev.psych.60.110707.163621

5. Barriball, KL and While, A. (1994) "Collecting data using a semi-structured interview: a discussion paper", Journal of Advanced Nursing, Vol. 19, No. 2, pp. 328-335. https://doi.org/10.1111/j.1365-2648.1994.tb01088.x 
6. Bass, B. M., and Bass, R. (2008), The Bass handbook of leadership: Theory, research and managerial applications (4th ed.). New York, NY: Free Press

7. Bass, B.M and Stogdill, R.M. (1990), Bass and Stogdill's handbook of leadership: theory, research, and managerial applications, New York: Free Press.

8. Bolden, R., and Gosling, J. (2006). "Leadership competencies: Time to change the tune?” Leadership, Vol. 2, No. 2, pp.147-163.

https://doi.org/10.1177/1742715006062932

9. Burns, J.M. (1978), Leadership, New York: Harper and Row.

10. Carbone, K. (2009), Evaluation of a leadership development program: investigating the impact and key factors facilitating or impeding success, $\mathrm{PhD}$ Thesis, New Brunswick: University of New Jersey. https://doi.org/doi:10.7282/T3ZG6S7J

11. Collins, D, and Holton, E. (2004) "The effectiveness of managerial leadership development programs: A meta-analysis of studies from 1982-2001", Human Resource Development Quarterly, Vol. 5, No. 2, pp. 217-248. https://doi.org/10.1002/hrdq.1099

12. Day, D. (2000), "Leadership development: A review in context", Leadership Quarterly, Vol 11, No. 4, pp 581-613. https://doi.org/10.1016/S10489843(00)00061-8

13. Downton, J. V. (1973), Rebel leadership: Commitment and charisma in an evolutionary process, New York: Free Press.

14. Dubai Strategic Plan (2015), Highlights of Dubai Strategic Plan, Available from: http://www.deg.gov.ae/SiteCollectionImages/Content/pubdocs/Dubai_Strategic_P lan_2015.pdf [Accessed 5 March 2015].

15. Fiedler, F. E. (1964) "A contingency model of leadership effectiveness", in: Meurant, G. (Ed), Advances in experimental social psychology, Academic Press, Vol. 1, pp 149-190.

16. Gibler, DJ, Carter, L, and Goldsmith, M (2000), Best practices in leadership development handbook. San Francisco: Jossey-Bass.

17. Herbert, K., Mockaitis, A. I., and Zander, L. (2014). "An opportunity for east and west to share leadership: A multicultural analysis of shared leadership preferences in global teams", Asian Business and Management, Vol 13, No. 3, pp.257-282. https://doi.org/10.1057/abm.2014.10

18. Hernez-Broome, G., and Hughes, RL. (2004), "Leadership development: Past, present, and future", Human Resource Planning, Vol 27, pp 24-32.

19. Hersey, P., and Blanchard, K. H. (1969), "Life-cycle theory of leadership", Training and Development Journal, Vol 23, No. 5, pp. 26-34.

20. Hofstede, G. (1980). "Motivation, leadership, and organisation: Do American theories apply abroad?", Organisational Dynamics, Vol. 9, No. 1, pp.42-63. https://doi.org/10.1016/0090-2616(80)90013-3 
21. Hofstede, G. (2013), "Replicating and Extending Cross-National Value Studies: Rewards and Pitfalls - An example for Middle East Studies", AIB Insights, Vol. 13, No. 2, pp. 5-7.

22. Hogan, R. (1994). "What We Know About Leadership: Effectiveness and Personality”, American Psychologist, Vol. 49, No. 6, pp. 493-504. https://doi.org/10.1037/0003-066X.49.6.493

23. House, R.J., Delbecq, A., and Taris, TW. (1996), Value based leadership: An integrated theory and an empirical test, Working Paper, Philadelphia: University of Pennsylvania.

24. House, RJ, Hanges, PJ, Ruiz-Quintanilla, SA, Dorfman, PW, Javidan, M, Dickson, M, Gupta, V, Brenk, KM, Konrad, E, and Sabdin, A. (1999), "Cultural influences on leadership and organisations: Project GLOBE”, in: Mobley, W. H., Gessner, M. J. and Arnold, V. (Ed), Advances in Global Leadership, UK: Emerald Group Publishing, pp. 171-233.

25. Iles, P., Almhedie, A., and Baruch, Y. (2012), "Managing HR in the Middle East: Challenges in the Public Sector", Public Personnel Management, Vol. 41, No.3, pp. 465-492. https://doi.org/10.1177/009102601204100305

26. Johnson, B., and Christensen, L. (2008) Educational research: quantitative, qualitative and mixed approaches, California: Sage Publications Inc.

27. Judge, TA, Bono, JE, Ilies, R and Gerhardt, MW. (2002), "Personality and Leadership: A Qualitative and Quantitative Review", Journal of Applied Psychology, Vol. 87, No. 4, pp. 765-780. https://doi.org/10.1037/00219010.87.4.765

28. Kennedy, F., Carroll, B., and Francoeur, J. (2012). "Mindset Not Skill Set: Evaluating in New Paradigms of Leadership Development", Advances in Developing Human Resources, Vol. 15, No. 1, pp.10-26. https://doi.org/10.1177/1523422312466835

29. Kim, AK and Maubourgne, RA. (1992), "Parables of Leadership", Harvard Business Review, Vol. 70, No. 4, pp. 123-128.

30. Klandermans, B. and Staggenborg, S. (2002), Methods of Social Movement Research, Minneapolis, University of Minnesota Press.

31. Kotter, JP. (1990), A Force for Change: How Leadership Differs from Management, New York: Free Press.

32. Kouzes, J, and Posner, B. (2002), The leadership challenge, $3^{\text {rd }}$ ed., San Francisco: Jossey-Bass.

33. Lee, M. (2014), "Transformational leadership: is it time for a recall?", International Journal of Management and Applied Research, Vol. 1, No. 1, pp. 17-29. https://doi.org/10.18646/2056.11.14-002

34. Leedy, P. D., and Ormrod, J. E. (2005), Practical research: planning and design, 8th ed., New Jersey: Prentice Hall. 
35. Leskiw, S., Singh, P. (2007), "Leadership development: learning from best practices", Leadership and Organisation Development Journal, Vol. 28, No. 5, pp 444-464. https://doi.org/10.1108/01437730710761742

36. Lowe, K. B, and Gardner, W.L. (2000). "Ten years of the Leadership Quarterly: contributions and challenges for the future", Leadership Quarterly, Vol. 11, pp.459-51. https://doi.org/10.1016/S1048-9843(00)00059-X

37. Madsen, S. R. (2010), "Leadership Development in the United Arab Emirates: The Transformational Learning Experiences of Women", Journal of Leadership \& Organizational Studies, Vol. 17, No. 1, pp. 100-110.

https://doi.org/10.1177/1548051809345254

38. Mameli, P. (2013), "Under New Management: What the Arab Spring Tells Us About Leadership Needs in the Middle East and North Africa", DOMES: Digest Of Middle East Studies, Vol. 22, No.2, pp. 377-404. https://doi.org/10.1111/dome.12026

39. Marmenout, K., and Lirio, P. (2014), "Local female talent retention in the Gulf : Emirati women bending with the wind", The International Journal of Human Resource Management, Vol. 25, No. 2, pp. 144-166. https://doi.org/10.1080/09585192.2013.826916

40. Maznevski ML, DiStefano JJ, Gomez CB, Noorderhaven NG, Wu P-C (2002) "Cultural dimensions at the individual level of analysis: the cultural orientations framework", International Journal of Cross Cultural Management, Vol. 2, No. 3, pp. 275-295. https://doi.org/10.1177/147059580223001

41. Mays, N., and Pope, C. (1995), "Qualitative research: rigour and qualitative research", BMJ, Vol. 311, No. 6997, pp109 - 112. https://doi.org/10.1136/bmj.311.6997.109

42. Mumford, M. (2000). "Leadership skills for a changing world: solving complex social problems", Leadership Quarterly, Vol.11, No. 1, pp.11-35. https://doi.org/10.1016/S1048-9843(99)00041-7

43. Myers, M.D. (2009), Qualitative Research in Business and Management, UK: Sage Publications.

44. Sarantakos, S. (2005), Social research, 3rd ed., New York: Palgrave Macmillan.

45. Sogunro, O.A. (1997), "Impact of training on leadership development: Lessons from a leadership training program", Evaluation Review, Vol. 21, No.6, pp713737. https://doi.org/10.1177/0193841X9702100605

46. Stogdill, R. M. (1948), "Personal factors associated with leadership: A survey of the Literature". Journal of Psychology, Vol. 25, No. 1, pp. 35-71. https://doi.org/10.1080/00223980.1948.9917362

47. Thach, L. and Heinselman, T. (2000) "Continuous improvement in place of training", In: Goldsmith; M.; Lyons; L. and Freas, A. (Ed.), Coaching for leadership: How the world's greatest coaches help leaders learn, San Francisco: Pfeiffer, pp. 219-230.

48. Weber, M (1947), The theory of social and economic organisations, (translated by Henderson, A. M. and Parson, T.). New York: The Free Press. 
Leadership Development Programs: Investigating the Impact of Contextual and Cultural Factors on LDP Effectiveness in United Arab Emirates

49. Weston, C, Gandell, T, Beauchamp, J, McAlpine, L, Wiseman, C and Beauchamp, C. (2001), "Analyzing Interview Data: The Development and Evolution of a Coding System", Qualitative Sociology, Vol. 24, No. 3, pp. 381-400. https://doi.org/10.1023/A:1010690908200 